УДК 655.3.06

( Т. Ю. Киричок, д-р техн. наук, проф., В. А. Баглай, аспірант, КПІ ім. Ігоря Сікорського, А. А. Безпалий, канд. техн. наук, старш. фахівець служби досліджень та розвитку технологій Банкнотно-монетного двору

Національного банку України, П. Г. Регіда, асист., КПІ ім. Ігоря Сікорського, Київ, Україна

\title{
МЕТОДИКА АВТОМАТИЗОВАНОГО ОЦІНЮВАННЯ ЯКОСТІ ТЕХНОЛОГІЧНОЇ ОПЕРАЦІї ПРЯМОГО ЛАЗЕРНОГО ГРАВІЮВАННЯ ФОРМ ІНТАГЛІОДРУКУ
}

Визначення якості відтворення отриманих методом прямого лазерного гравіювання (DLE - Direct Laser Engraving) штрихів

форми інтагліодруку та її залежності від запроектованих параметрів профілю є актуальним завданням, що дозволить удосконалити режими оброблення форм DLE та розширить

її використання у виробництві захищеної поліграфічної продукції.

Достовірне визначення параметрів гравійованих штрихів форми після технологічного етапу DLE дозволить цілеспрямовано впливати на тиражостійкість форм інтагліодруку.

Тому метою дослідження було розроблення програмного засобу для повної або часткової автоматизації процесу оцінки результатів лазерного гравіювання та встановлення за його допомогою відповідності перетину гравійованого штриха форми запроектованому.

Ключові слова: інтагліодрук; пряме лазерне гравіювання; друкувальні елементи; гравійовані штрихи; тиражостійкість; латунь.

\section{Постановка проблеми}

Пряме лазерне гравіювання (DLE - Direct Laser Engraving) $€$ найсучаснішою технологією виготовлення форм інтагліодруку. Лазерне гравіювання є першим, не рахуючи етапу дизайну форм, етапом технологічного процесу, під час якого мають бути максимально дотримані запроектовані параметри гравійованих штрихів, котрі визначають як тактиль- ність відбитків (ключову захисну ознаку, яку забезпечує інтагліодрук), так і їх колірні характеристики. Тому визначення якості відтворення гравійованих штрихів та її залежності від запроектованих параметрів профілює актуальним завданням, що дозволить удосконалити режими оброблення форм DLE та розширить її використання у виробництві захищеної поліграфічної продукції. 


\section{Аналіз попередніх досліджень}

Інтагліодрук вже десятиліття залишається однією з найбільш розпізнаваних населенням захисних ознак високозахищеної поліграфічної продукції, зокрема, банкнотної [1-3]. Тому використання цього способу друку є рекомендованим Інтерполом [4], і використовується усіма державами світу для захисту власної валюти від підроблення як однобічне задруковування, так і двобічне [5]. Незважаючи на традиційність цього методу захисту, технологія інтагліодруку постійно розвивається.

Оскільки найсучасніший спосіб виготовлення форм інтагліодруку - технологія DLE, незважаючи на низку переваг та технологічних можливостей порівняно з іншими технологіями $[6,7]$, має певні особливості, що можуть викликати зниження тиражостійкості форм порівняно із традиційними технологіями виготовлення форм: обробку латунної пластини лазером та подальше нанесення захисного нітрид-хромового покриття вакуумним напиленням (PVD) [8, 9]. Тому технологія прямого лазерного гравіювання з подальшим нанесенням захисного нітрид-хромового покриття PVD потребує удосконалення режимів оброблення форм та PVD. У попередніх дослідженнях нами проаналізовано та визначено основні групи факторів, які впливають на тиражостійкість форм інтагліодруку: параметри процесу DLE (спосіб видалення напливів металу у процесі лазерного гравіювання); параметри форми інтагліодруку (спосіб виготовлення (традиційний чи DLE), параметри штрихів форми інтагліодруку (їх ширина, довжина, глибина, відстань між штрихами, вид профілю (трапецієподібний, прямокутний), симетричність профілю (симетричний, асиметричний)); параметри процесу вакуумного напилення (температура підложки (форми під час напилення), шорсткість пробільних та друкувальних елементів, товщина нітрид-хромового покриття, режимів травлення підложки в камері напилення, відсотковий склад газової суміші $\mathrm{Ar}-\mathrm{N}_{2}$ в камері напилення) [10].

Отже, достовірне визначення параметрів гравійованих штрихів форми після технологічного етапу DLE дозволить цілеспрямовано впливати на тиражостійкість форм інтагліодруку.

\section{Мета роботи}

Розробка програмного засобу (ПЗ) для повної або часткової автоматизації процесу оцінки результатів лазерного гравіювання та встановлення за його допомогою відповідності перетину гравійованого штриха форми запроектованому.

\section{Результати проведених досліджень}

Модельна форма з вісьмома плашками, кожна з яких являє собою сукупність 30 гравійованих штрихів з параметрами, наведеними в табл. запроектовано і виготовлено фахівцями Банкнотномонетного двору Національного банку України з використанням системи прямого лазерного гравіювання Jura JSP Direct Laser Engraver (тип лазера - неодимовий (Nd:YAG, алюмо-іттриєвий гранат легований іонами неодиму); 
довжина хвилі 1064 нм; потужність 1,77 кВт; матеріал пластини - латунь; товщина пластини 0,977-1,032 мм, область гравіювання - 54×54 мм. Для проведення досліджень на латунній пластині із використанням різних режимів лазерного гравіювання (режими: H3L - видаляє шар товщиною 2 мкм за прохід; Н3М видаляє шар товщиною 4 мкм за прохід; Н3Н - видаляє шар товщиною 8 мкм за прохід) було вигравійовано вісім ідентичних ділянок (плашок) з набором друкарських елементів з різною геометрією поперечних профілів (табл.).

Із зазначених ділянок відповідно до стандартних методик підготовлено металографічні шліфи перпендикулярно до площини пластини і гравійованих штрихів. Одержані в такий спосіб зразки досліджено за допомогою оптичного металографічного мікроскопу.

Для дослідження мікроструктури форм використано методи оптичної металографії із застосуванням фотомікроскопа віддзеркаленого світла Neophot-32, який дає можливість досліджувати травлені та нетравлені мікрошліфи та фотографувати їх зі збільшенням до ×1000 [11, 12].

Мікрошліфи було підготовлено за стандартними методиками [13-15].

Дослідженнями встановлено, що всі гравійовані штрихи зразка мають суттєві відхилення від заданого геометричного профіля і зазвичай $є$ несиметричними. Тому розроблено методику, яка на основі розробленого програмного забезпечення дозволяє на основі різниці кольорів пікселів латуні та чорного тла шліфів встановити реальні параметри профілю.

Первинний аналіз графічних файлів шліфів гравійованих штрихів дозволяє визначити їх характерні риси: зображення утворені переважно двома типами пікселів - світлими (латунь) та темними (тло для фотографування), тому, враховуючи суттєву криволінійність стінок штрихів, а також часто наявну асиметрію, площу перетину гравійованого штриха форми доцільно встановити, аналізуючи саме кількість та розмір (за масштабом) темних пікселів зображення. Подальший аналіз графічних файлів шліфів гравійованих штрихів показав, що вони не лише суттєво різняться за формою, але й отримані за різних кутів зйомки, кожен знімок має свій унікальний набір шумів у зображенні тощо. Це дозволяє зробити висновок про можливість розробити додаток для часткової автоматизації процесу оцінювання площі перетину гравійованого штриха форми, коли розроблена система може використовуватись для виконання основних математичних обрахунків, однак потребує корегування налаштувань для кожного окремого графічного файла фахівцем.

Для виконання поставленого завдання було обрано мови програмування та інструменти розробки, розроблено алгоритм для автоматизованого оцінювання якості технологічної операції прямого лазерного гравіювання форм інтагліодруку: проведено тестування роботи ПЗ та впроваджено розроблене ПЗ для оцінювання площі перетину гравійованого штриха форми. 
Для вирішення поставленої задачі розроблено додаток з робочою назвою DLEScript, для чого використано мову програмування JavaScript, за допомогою якого можлива маніпуляція Canvas з використанням тегу <canvas>, що є елементом специфікації HTML5. Основним призначенням Canvas
$€$ створення двовимірних растрових зображень. Такий набір інструментів дозволить маніпулювати отриманими зображеннями для пошуку площі перетину гравійованого штриха.

Алгоритм роботи додатку, фактично, представлений на початковому інтерфейсі (рис. 1, а):

Опис досліджуваних зразків

\begin{tabular}{|c|c|c|c|c|c|c|c|c|c|c|c|c|c|c|c|}
\hline $\begin{array}{c}\text { Номер } \\
\text { штриха } \\
\text { в плашці }\end{array}$ & 1 & 2 & 3 & 4 & 5 & 6 & 7 & 8 & 9 & 10 & 11 & 12 & 13 & 14 & 15 \\
\hline $\begin{array}{c}\text { Глибина } \\
\text { штриха, a }\end{array}$ & & \multicolumn{3}{|c|}{20} & \multicolumn{3}{|c|}{30} & \multicolumn{3}{|c|}{60} & \multicolumn{2}{|c|}{40} & \multicolumn{3}{|c|}{40} \\
\hline $\begin{array}{c}\text { Ширина } \\
\text { штриха, b }\end{array}$ & & \multicolumn{3}{|c|}{30} & \multicolumn{3}{|c|}{30} & \multicolumn{3}{|c|}{60} & \multicolumn{2}{|c|}{40} & \multicolumn{3}{|c|}{40} \\
\hline $\begin{array}{l}\text { Кут нахилу } \\
\text { стінок } \\
\text { штриха, } \alpha\end{array}$ & & & & & & & & & & & & & & 60.00 & \\
\hline $\begin{array}{c}\text { Площа пере-- } \\
\text { тину штриха } \\
\text { теоретична }\end{array}$ & & \multicolumn{3}{|c|}{600} & \multicolumn{3}{|c|}{900} & \multicolumn{3}{|c|}{3600} & \multicolumn{2}{|c|}{1600} & \multicolumn{3}{|c|}{1080.4} \\
\hline \multicolumn{16}{|l|}{$\begin{array}{c}\text { Заданий про- } \\
\text { філь пере- } \\
\text { тину штриха }\end{array}$} \\
\hline $\begin{array}{c}\text { Потужність } \\
\text { гравіювання }\end{array}$ & $\begin{array}{l}\stackrel{I}{M} \\
\stackrel{M}{I}\end{array}$ & $\overrightarrow{\underline{m}}$ & $\sum_{\substack{1 \\
I}}$ & $\stackrel{\underline{I}}{\stackrel{M}{I}}$ & $\vec{m}$ & $\sum_{\substack{1 \\
1}}$ & $\begin{array}{l}\frac{I}{M} \\
\stackrel{M}{I}\end{array}$ & $\sum_{\substack{\text { M } \\
\text { I. }}}$ & $\stackrel{\frac{I}{M}}{\underline{M}}$ & $\overrightarrow{\mathrm{m}}$ & $\sum_{\frac{m}{I}}$ & $\begin{array}{l}\frac{I}{M} \\
\stackrel{M}{I}\end{array}$ & ले & $\sum_{\substack{1 \\
I}}$ & $\stackrel{\frac{T}{m}}{\frac{m}{I}}$ \\
\hline $\begin{array}{c}\text { Номер } \\
\text { штриха } \\
\text { в плашці }\end{array}$ & 16 & 17 & 18 & 19 & 20 & 21 & 22 & 23 & 24 & 25 & 26 & 27 & 28 & 29 & 30 \\
\hline $\begin{array}{c}\text { Глибина } \\
\text { штриха, а }\end{array}$ & \multicolumn{3}{|c|}{40} & \multicolumn{2}{|c|}{80} & \multicolumn{2}{|c|}{80} & \multicolumn{2}{|c|}{80} & \multicolumn{2}{|c|}{100} & \multicolumn{2}{|c|}{100} & \multicolumn{2}{|c|}{100} \\
\hline $\begin{array}{c}\text { Ширина } \\
\text { штриха, b }\end{array}$ & \multicolumn{3}{|c|}{40} & \multicolumn{2}{|c|}{100} & \multicolumn{2}{|c|}{100} & \multicolumn{2}{|c|}{100} & \multicolumn{2}{|c|}{100} & \multicolumn{2}{|c|}{100} & \multicolumn{2}{|c|}{100} \\
\hline $\begin{array}{l}\text { Кут нахилу } \\
\text { стінок } \\
\text { штриха, } \alpha\end{array}$ & \multicolumn{3}{|c|}{75.00} & & & \multicolumn{2}{|c|}{60.00} & \multicolumn{2}{|c|}{75.00} & & & \multicolumn{2}{|c|}{60.00} & 75 & .00 \\
\hline $\begin{array}{c}\text { Площа пере- } \\
\text { тину штриха } \\
\text { теоретична }\end{array}$ & & 58.8 & & & & 517 & 1.3 & 690 & 2.4 & & & 532 & 3.6 & 810 & 9.16 \\
\hline $\begin{array}{c}\text { Заданий про- } \\
\text { філь пере- } \\
\text { тину штриха }\end{array}$ & & & & & & & & & & & & & & & \\
\hline $\begin{array}{c}\text { Потужність } \\
\text { гравіювання }\end{array}$ & $\overrightarrow{\text { m}}$ & $\sum_{\substack{\text { M } \\
\text { I }}}$ & $\stackrel{\underline{I}}{\mathrm{M}}$ & $\sum_{\text {M }}^{\text {I }}$ & $\stackrel{\mathrm{I}}{\mathrm{m}}$ & $\sum_{\substack{1 \\
I}}$ & $\frac{\mathrm{I}}{\mathrm{M}}$ & 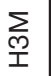 & $\begin{array}{l}\stackrel{I}{M} \\
\stackrel{M}{I}\end{array}$ & $\sum_{\substack{1 \\
I}}$ & $\begin{array}{l}\text { I } \\
\text { M }\end{array}$ & $\sum_{\substack{1 \\
I}}$ & $\stackrel{\mathrm{I}}{\mathrm{M}}$ & 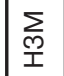 & $\frac{I}{M}$ \\
\hline
\end{tabular}


пошук зображення для аналізу етап Image Parser (рис. 1, б); завантаження зображення для аналізу - етап Original image (рис. 1, в); встановлення масштабу зображення - етап Scale image (рис. 1, г); виокремлення частини зображення для маніпулювання Canvas - етап Cutted image

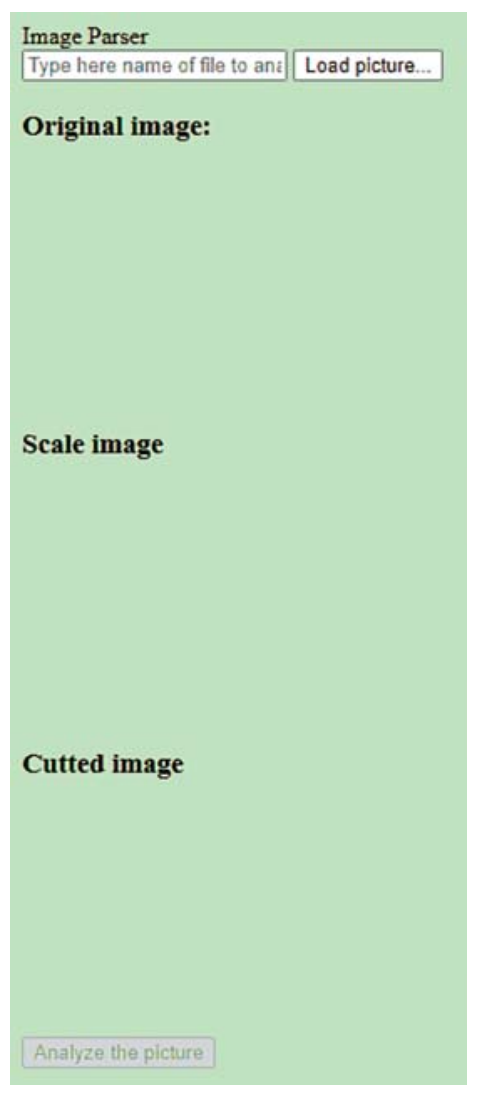

a

Рис 1. Інтерфейс додатку DLEScript: a - початковий інтерфейс; б - пошук файлу зображення; в - готове до опрацювання зображення; г - масштабування зображення; д - зображення після відсікання (рис. 1, д); аналіз кількості «темних» пікселів та визначення їх сумарної площі з урахуванням масштабу - етап Analyze the picture (кнопка запуску обчислень, рис. 1, а).

Інтерфейс додатку простий та наочний: основна ідея його полягає у поетапній візуалізації
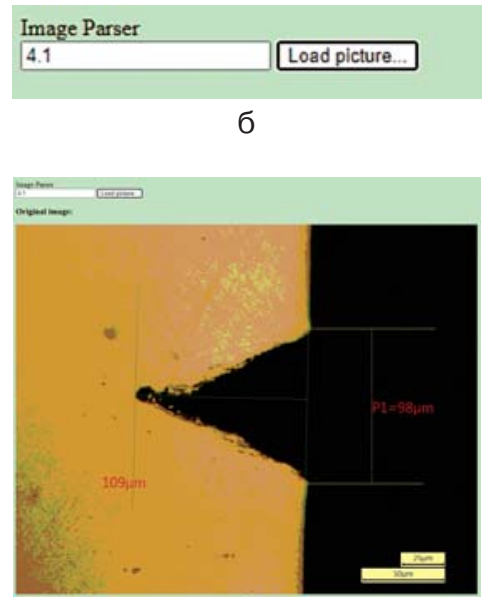

B

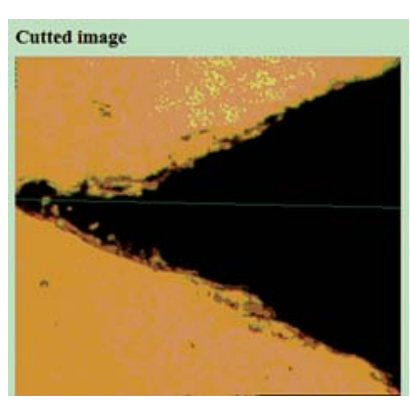

Д

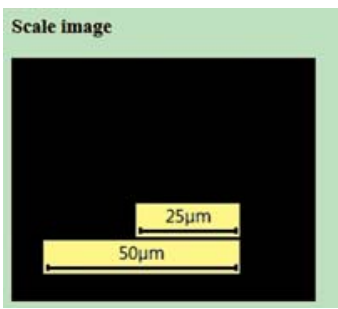

$\Gamma$

\section{$+$

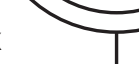

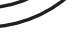


перебігу аналізу зображення. Інтерфейс орієнтований на роботу із одним зображенням.

Етап Image Parser. Для початку роботи з додатком, необхідно ввести ім'я графічного файлу, який потрібно проаналізувати (рис. 1, б). Це можна реалізувати двома шляхами: 1) з використанням можливостей тега <form> специфікації HTML5 (зазначаючи тип файлу як графічний <input type="file" accept="image/*">, або вказавши допустиме розширення файлу (<input type="file" accept=".jpg">)); 2) за умови відомого імені файлу - запустивши алгоритм перевірки наявності такого файлу у системі, який завантажить зображення для опрацювання у додатку або сповістить користувача про його відсутність; для зручності було реалізовано функцію додавання розширення файлу, якщо його не було введено користувачем. Для прикладу, ім'я файлу 4.1.jpg, користувач може ввести як $\mathrm{i}$ «4.1», так $\mathrm{i}$ «4.1.jpg», описана функція проаналізує запис користувача та, якщо це необхідно (у першому випадку) додасть розширення файлу для коректного пошуку файлу.

Етап Original image. Інтерфейс програми, коли зображен- ня для аналізу було знайдено та завантажено у вікно додатку наведено на рис. 1 , в.

Етап Scale image. За умови, якщо файл був знайдений, пЗ переходить до наступного кроку ініціалізації нових графічних об'єктів, де буде розміщувати результати своєї роботи. Перший крок це пошук на зображенні у вікні програми масштабної лінійки для правильного визначення розміру пікселя. Для цього програма відсікає певну частину зображення, для того щоб отримати менше зображення тільки із масштабною лінійкою (рис. 1, г).

Наступний крок - аналіз зображення із масштабною лінійкою. За допомогою реалізованих алгоритмів, отримане зображення розбивається на горизонтальні лінії наборів пікселів. Серед отриманих ліній виконується пошук такої, яка містить найбільшу кількість «темних» пікселів. Отримане значення таких пікселів дозволяє отримати розмір сторони пікселя. Код пошуку представлено на рис. 2.

Слід зауважити, що тут знадобиться підтримка фахівця: для пошуку області із масштабною лінійкою ПЗ використовує стандартне число 25 \%. Цей відсоток визначає частку (довжину

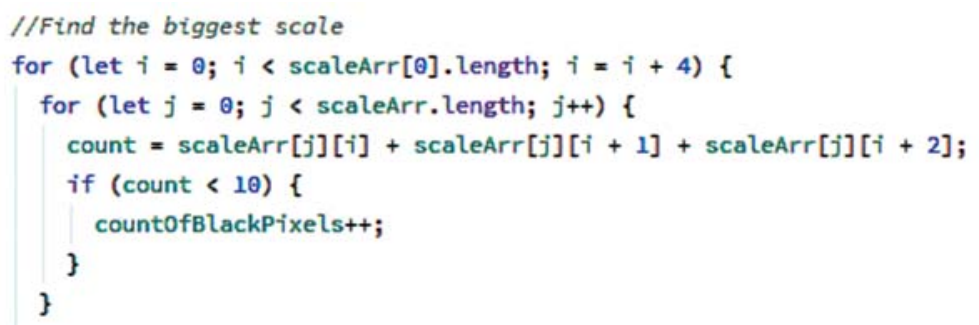

Рис. 2. Визначення розміру пікселя за масштабною лінійкою зображення 
і ширину) оригінального зображення, яку потрібно відрізати, щоб отримати зображення тільки із масштабною лінійкою. Іноді, за умови використання стандартного значення, у зображення будуть потрапляти сторонні об'єкти, порушуючи точність пошуку розміру пікселя. Тому, фахівець має контролювати і, за потреби, корегувати, яку частку оригінального зображення потрібно відрі- зати, щоб отримати зображення тільки із масштабною лінійкою (маніпулюючи, доки на результуючому зображенні не буде розміщена тільки масштабна лінійка).

Етап Cutted image. Далі, щоб отримати шукану площу, програма повинна позбутись зайвих частин на зображенні, що подається на аналіз. Для цього потрібно реалізувати алгоритм пошуку горизонтальних ліній,
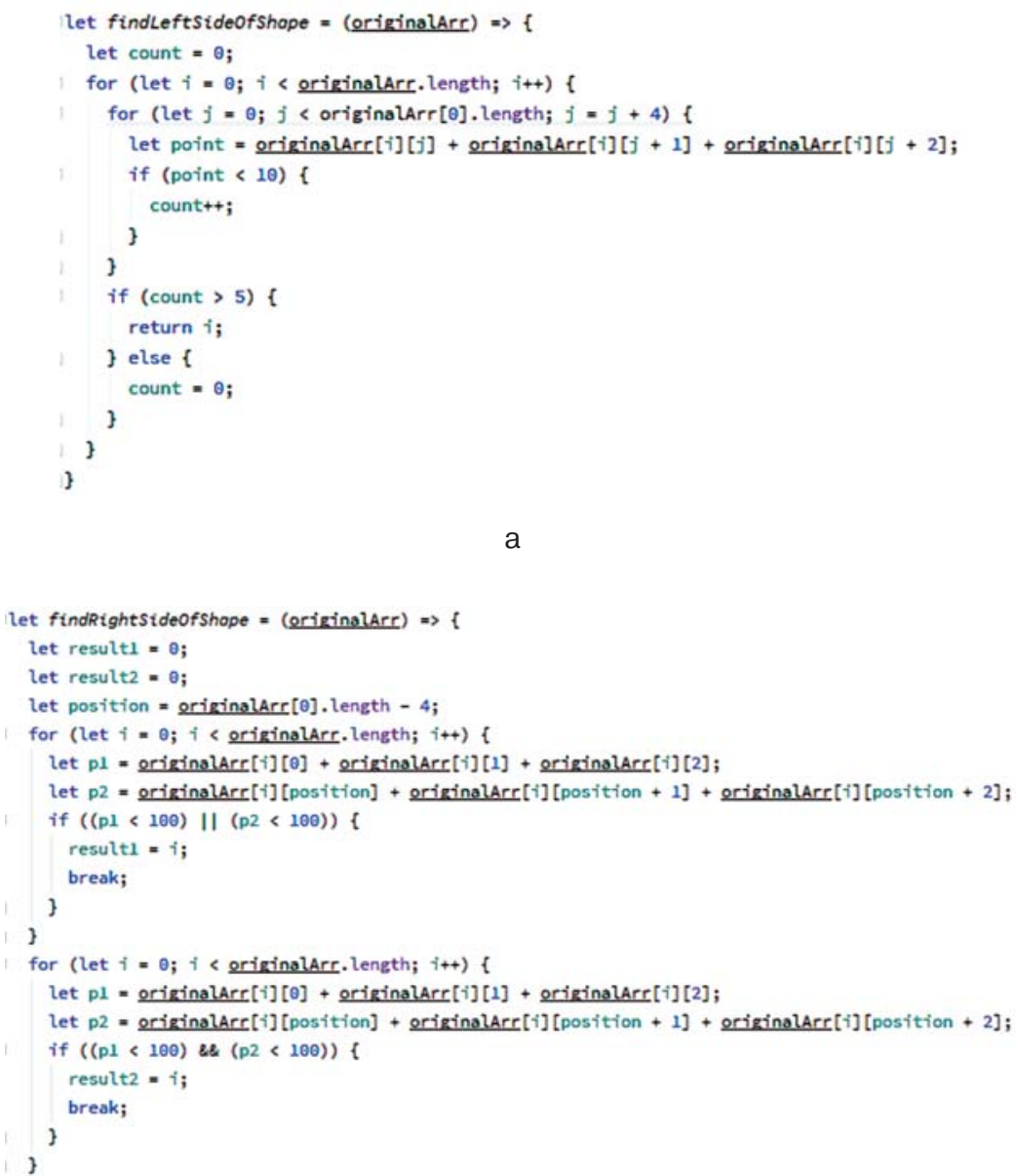

Рис. 3. Алгоритм виокремлення зображення: a - відсікання лівої частини; б - відсікання правої частини 
що «відріжуть» ліву та праву непотрібні для аналізу частини. Ліва частина зображення являє собою масив латунного листа від дна гравійованого штриха, а права - окреслюється площиною пробільних елементів та продовжується темним тлом. Для пошуку лівої частини зображення використано алгоритм (рис. 3, а) розбиття вхідного зображення на вертикальні лінії пікселів, серед яких виконується пошук «темних» пікселів певної кількості.

Цим значенням теж повинен оперувати фахівець для отримання найбільшої точності. Як показала практика, число 10 (кількість чорних пікселів) на цьому етапі виконання програми підходить в $90 \%$ випадків, і не потребує змін. Після прорахованої позиції вертикальної лінії, ліва частина обрізається.

Пошук відсікання правої сторони виконується за таким же принципом, але потребує додаткових обчислень (рис. 3, б), оскільки на частині отриманих зо- бражень видно, що шліф розміщений під кутом, що ускладнює пошук площі. Тому, ми шукаємо дві вертикальні лінії із такими ознаками: перша має мати хоча б один перший або останній «темний» піксель, це означає що програма знайшла пробільний елемент форми, друга характеризується першим і останнім «темним» пікселем у лінії. Такий підхід використовується для зменшення похибки.

Для більш точної обробки результуюча лінія розрізу зображення знаходиться у позиції середнього арифметичного першої позиції лінії та другої позиції лінії (рис. 1, д).

Етап Analyze the picture. Після обробки зображення з урахуванням встановленого за масштабом на попередніх кроках розміру пікселя зображення визначаємо площу перетину гравійованого штриха за кількістю «темних» пікселів.

За підсумками оброблення зображень шліфів було встановлено фактичну площу перетину

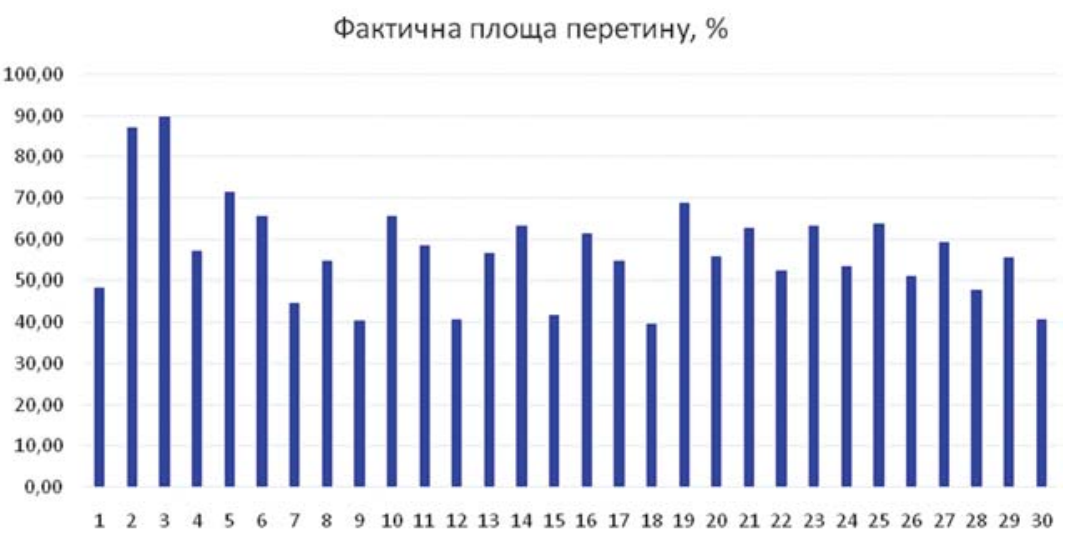

Рис. 4. Фактична площа перетину штрихів модельної форми порівняно із запроектованим профілем 
гравійованих штрихів форми порівняно із запроектованою, наведеною в табл. (рис. 4). Через суттєве відхилення профілю від запроектованого площа перетину штрихів перебуває в межах 40-90 \% від запроектованого. Найкращі геометричні параметри мають прямокутні штрихи невеликого розміру. Зниження потужності випромінювання під час гравіювання дозволяє забезпечити кращу якість відтворення геометричних параметрів штриха.

\section{Висновки}

Дослідження методом оптичної металографії шліфів гравійованих штрихів тридцяти видів, що відрізнялися запроектованим профілем (глибиною (20-100 мкм), шириною (30-100 мкм), кутом нахилу стінок штриха (600-900)) та потужністю гравіювання, утворених методом DLE на латунній пластині, показало, що всі гравійовані штрихи зразка мають суттєві відхилення від заданого геометричного профілю і зазвичай $є$ несиметричними. Тому для визначення реальних параметрів штрихів запропоновано методику, яка за допомогою роз- робленого програмного забезпечення дозволяє на основі урахування різниці кольорів пікселів латуні та чорного тла шліфів визначити реальні параметри штрихів.

Запропонована методика реалізована програмно в розробленому додатку DLEScript, для чого використано мову програмування JavaScript, за допомогою якого можлива маніпуляція Canvas з використанням елементу специфікації HTML5 <canvas>.

Оброблення зображень шліфів у розробленому додатку дозволило встановити фактичну площу перетину гравійованих штрихів форми порівняно із запроектованою: через суттєве відхилення профілю від запроектованого площа перетину штрихів перебуває в межах 40-90 \% від запроектованого. Найкращі геометричні параметри мають прямокутні штрихи невеликого розміру. Зниження потужності випромінювання під час гравіювання дозволяє забезпечити кращу якість відтворення геометричних параметрів штриха. Це дозволяє цілеспрямовано корегувати процес гравіювання DLE.

\section{Список використаної літератури}

1. DeHeij H. Banknote design for retailers and public / H. deHeij // DNB Occasional Studies. De Nederlandsche Bank NV, 2010. Vol. 8(4). P. 161-164.

2. Banknotes: under- or over-featured? / Infosecura Banknote Printing [Електронний ресурс]. November 2014. No. 62. Р. 6-9. Режим доступу: http://www. securityprinters.org/dwl/Infosecura62.pdf.

3. Bender K. W. Money makers. The secret world of banknote printing / K. W. Bender. Wiley-VCH, 2006. 317 p.

4. Interpol Resolution No AGN/67/RES/11: 9th International Conference on Currency Counterfeiting, the ICPO-Interpol General Assembly, 67th session. [Електронний ресурс]. Cairo, Egypt. October 22-27, 1998. Режим доступу: https://www.interpol.int/content/dow.

5. Treinen $\mathrm{H}$. Research endorses the value of two-sided intaglio / $\mathrm{H}$. Treinen // Currency News. 2005. Vol. 3(2). February. pp. 10-11. 
6. Пат. 20110250410 Канада, МПК В32B 03/10, C08L 33/08, B41M 01/12, B05D 03/06. Method and composition for printing tactile marks and security document formed therefrom / T. P. Rygas, Th. Thurailingam, S. Crisan, N. J. Sylvain; заявник і патентовласник Canadian BankNote Company, Limited; заявл. 21.12.2009; опублік. 26.10.2011.

7. Пат. 20040061325 Канада, МПК В42D15/00. Printed security device and method / E. A. Lyen, L. M.-F. Suzzarini; заявник і патентовласник Canadian BankNote Company, Limited; заявл. 07.09.2002; опублік. 01.04.2004.

8. Пат. 2384890 США, МПК B41F 13/187, B41M 3/14, B41M 1/10, B41N 10/04. Impression cylinder for intaglio printing and intaglio printing process / M. Gygi; заявник і патентовласник KBA-Giori S.A.; заявл. 07.05.2010 р.; опублік. 28.08.2011.

9. Пат. 20110058509 США, МПК В29С35/08. Method and system for manufacturing intaglio printing plates for the production of security papers / J. Perrier; № 12/992522; заявник і патентовласник KBA-GIORI S.A.; заявл. 5.05.2009; опублік. 24.03.2011.

10. Киричок Т. Ю. Система формування тиражостійкості форм інтагліодруку / Т. Ю. Киричок, В. А. Баглай // Технологія і техніка друкарства. 2019. Вип. 3(65). C. 15-24. DOI: https://doi.org/10.20535/2077-7264.3(65).2019.196565.

11. Роїк Т. А. Композиційні підшипникові матеріали для підвищених умов експлуатації: монографія / Т. А. Роїк, П. О. Киричок, А. П. Гавриш. К.: НТУУ «КП|», 2007. 404 c.

12. ISO 14577-1:2015. Metallic materials - Instrumented indentation test for hardness and materials parameters - Part 1: Test method.

13. ДСТу 7175:2010 Метали і сплави. Методи металографічного контролювання. Терміни та визначення понять; ISO/CD TR 20580.

14. Preparation of metallographic specimens; ISO 4499-1:2008(en). Hard metals - Metallographic determination of microstructure - Part 1: Photomicrographs and description.

15. ISO 3057:1998(en). Non-destructive testing - Metallographic replica techniques of surface examination.

\section{References}

1. DeHeij, H. (2010). Banknote design for retailers and public. Journal of DNB Occasional Studies. De Nederlandsche Bank NV, Vol. 8(4), 161-164 [in English].

2. (2014). Banknotes: under- or over-featured? Infosecura Banknote Printing, November, No. 62, 6-9. Retrieved from: http://www.securityprinters.org/ dwl/Infosecura62.pdf [in English].

3. Bender, K. W. (2006). Money makers. The secret world of banknote printing. Wiley-VCH, 317 p. [in English].

4. (1998). Interpol Resolution No AGN/67/RES/11. 9th International Conference on Currency Counterfeiting, the ICPO-Interpol General Assembly, 67th session. Cairo, Egypt. Retrieved from: https://www.interpol.int/content/dow [in English].

5. Treinen, H. (2005). Research endorses the value of two-sided intaglio. Journal of Currency News, Vol. 3(2), 10-11 [in English].

6. Rygas, T. P. \& Thurailingam, Th. \& Crisan, S. \& Sylvain, N. J. Method and composition for printing tactile marks and security document formed therefrom // Patent № 20110250410. Publish 26.10.2011 [in English].

7. Lyen, E. A. \& L. Suzzarini, M.-F. Printed security device and method // Patent № 20040061325. Publish 01.04.2004 [in English].

8. Gygi, M. Impression cylinder for intaglio printing and intaglio printing process // Patent № 2384890. Publish 28.08.2011 [in English]. 
9. Perrier, J. Method and system for manufacturing intaglio printing plates for the production of security papers // Patent № 20110058509. Publish 24.03.2011 [in English].

10. Kyrychok, T. Yu. \& Bahlai, V. A. (2019). Systema formuvannia tyrazhostiikosti form intahliodruku. Journal of Tekhnolohiia i tekhnika drukarstva, 3(65), 15-24. DOI: https://doi.org/10.20535/2077-7264.3(65).2019.196565 [in Ukrainian].

11. Roik, T. A. \& Kyrychok, P. O. \& Havrysh, A. P. (2007). Kompozytsiini pidshypnykovi materialy dlia pidvyshchenykh umov ekspluatatsii. Kyiv: NTUU 'KPI', 404 p. [in Ukrainian].

12. ISO 14577-1:2015. Metallic materials - Instrumented indentation test for hardness and materials parameters - Part 1: Test method [in English].

13. National standards of Ukraine. (2010). DSTU 7175:2010: Metaly i splavy. Metody metalohrafichnoho kontroliuvannia. Terminy ta vyznachennia poniat; ISO/CD TR 20580 [in Ukrainian].

14. ISO 4499-1:2008(en). Preparation of metallographic specimens; Hard metals - Metallographic determination of microstructure - Part 1: Photomicrographs and description [in English].

15. ISO 3057:1998(en). Non-destructive testing - Metallographic replica techniques of surface examination [in English].

Determining the quality of reproduction obtained by direct laser engraving (DLE - Direct Laser Engraving) engravings of the intaglio printing plates and its dependence on the designed profile parameters is an urgent task that will improve the processing of DLE forms and expand its use in the production of securities.

Reliable determination of the parameters of the engravings of the printing plates after the technological stage of DLE will allow us to purposefully influence the circulation stability of the intaglio printing plates. Therefore, the aim of the study was to develop a software for full or partial automation of the process of evaluating the results of laser engraving and establishing with its help the correspondence of the cross-section of the engravings to the designed ones.

Keywords: intaglio printing; direct laser engraving; space element; printing element; engravings; run-length; brass.

Рецензент - Н. Л. Талімонова, канд. техн. наук, доц., КПІ ім. Ігоря Сікорського 